\title{
ANALYSIS AND CLASSIFICATION OF COMPANIES ON TEHRAN STOCK EXCHANGE WITH INCOMPLETE INFORMATION
}

\author{
Alireza Komeili Birjandi ${ }^{1}$, Sanaz Dehmolaee ${ }^{2}$, Reza Sheikh $^{1}$ And \\ SHIB SANKAR SANA ${ }^{3, *}$
}

\begin{abstract}
Due to uncertainty and large number of companies in financial market, it has become difficult to choose the right stock to investments. Identifying and classifying stocks using fundamental criteria help investors to better understand the risks involved in selecting companies and better manage their own capital, thereby rapidly and accurately choose their preferred stock and make more secure profit. The main concern that capital market investors are facing difficulty to choosing the right stock despite the uncertainties in the market. Uncertainties in the market that lead to incomplete information are presented in this article to complete the reciprocal preference relation method. The purpose of this paper is to present a method for completing information to reduce the uncertainties in the market and finally classify companies in each industry based on fundamental criteria. The classification method used is acceptability/reject ability which is based on distance fuzzy analysis yields more accurate results. Finally, a case study on one of the most critical industries in Tehran Stock Exchange is presented to show the effectiveness of the proposed approach.
\end{abstract}

Mathematics Subject Classification. 90B60, 90B50.

Received August 5, 2020. Accepted October 6, 2020.

\section{INTRODUCTION}

A major challenge that most investors face in stock market is choosing the stock with the best price at the best time possible [7,31]. Fuzzy classification helps investors to make better and faster selection of stocks in the Stock Exchange market considering their capital and the risk of stocks [11,32]. This choice is made using technical or fundamental analysis $[1,34,44]$. There are many analytical approaches for decision making in stock market, which are categorized in two groups: technical analysis and fundamental analysis [8,34]. We shall discuss these two groups in the following paragraphs.

Keywords. acceptability, reject ability, stock market, classification.

1 Industrial Engineering And Management, Shahrood University of Technology, Shahrood, Iran.

2 Management Sciences, Kharazmi University, Tehran, Iran.

3 Kishore Bharati Bhagini Nivedita College, Ramkrishna Sarani, Behala, Kolkata 700060, India.

*Corresponding author: shib_sankar@yahoo.com 
Technical analysis of stocks. Technical analysis is the study of past price movements to predict future prices using charts which demonstrate prices over time. This method is applicable to stocks, indices or commodities in which the price is influenced by the forces of supply and demand. In fact, technical analysis tries to predict future prices using iterative patterns such as recurring and continuing movements as well as indicators $[1,34,44]$.

Fundamental analysis. This is a method of measuring securities value by examining key financial and economic factors including revenue and profitability or even the effectiveness of the company's management which affect future prices. This approach is based on a key assumption that the performance of a company's stock can fully reflect its operating conditions $[3,8,31,34]$.

Fuzzy methods have been used in many studies, including classification problems, examples of which are given below.

Syed Abou Iltaf Hussai et al. [19] presented a strong multi-criteria decision model which evaluated alternatives versus criteria based on distance-based methods (PIVIFN) considering the uncertain nature of the decision makers. Other fuzzy decision-making problems included Neha Ghorui et al's work which used combined fuzzy AHP and topsis methods to select a location for a store in India, taking into account various influential criteria in re-selection [17]. Applying Fuzzy Regression Analysis Method, Al-Dini et al. [3] showed that, in Khodro, Iran EPS (earnigs per share) and DPS (dividend per share) are correlated to the stock prices.

Sayumwe and Amroune [40] and Warrad [1,47] proved that fundamental factors could be used to predict future stock price. Emir et al. [12] and Ayodele et al. [6] proposed an integrated model comprising of fundamental and technical factors which could provide a better prediction of stock prices rather than fundamental or technical factors alone can do [7].

Existing literature in Forex, Egyptian and Turkish stock market showed that combination of technical and fundamental analysis could provide a more accurate classification of stocks and prediction of price movements than technical or fundamental analysis individually [8].

In economic order quantity, Maity et al. [25] concluded that in cases with ambiguity, fuzzy methods yield better (more reliable) results than other methods do [25]. Due to the complexity of the market and the impact of a wide variety of conditions on stock classification, different criteria are needed in order to evaluate and compare companies, and consequently there will be a multi-criteria problem [15,22]. In this study, the criteria for evaluating companies mostly include fundamental analysis factors, however, because of the benefits of technical analysis, one of the criteria has been devoted to technical analysis and presented as experts' opinions of stocks. Moreover, due to the uncertainty in stock market [13,27], large number of companies in the market and a variety of technical analysis methods [4], experts are unable to assign precise ratings to some companies and as a result there is incomplete information in the experts' opinions and the information is completed applying the RPR method [51].

After the information is completed, a new classification method, a modified version of the method proposed by Tchangani [42] based on distance fuzzy method, is presented which eliminates the two major flaws in Tchangani's method [42].

Since stock selection should be done at as little time as possible and there are a large number of companies in the market, motivation for this research is to provide a suitable method for investors to choose stocks from different companies as quickly as possible. This work is innovative in the method used which is improved version of the Tchangani's method. The new method can be used in various decision-making contexts. Moreover, at the end of the article, the classification of petrochemical companies in the Tehran Stock Exchange considering incomplete information is presented so that people can make a better decision in their investment.

In this article, at first criteria specified by the stock market experts are defined and in the second part, a method is provided to complete incomplete information in the experts' ratings. After completing the information in the input matrix, in the third section, a new distance fuzzy method for classification is presented and eventually in the last section, the case study of the problem in petrochemical companies in Tehran exchange market is examined. The steps of the method are shown in the Figure 1 given as below. 


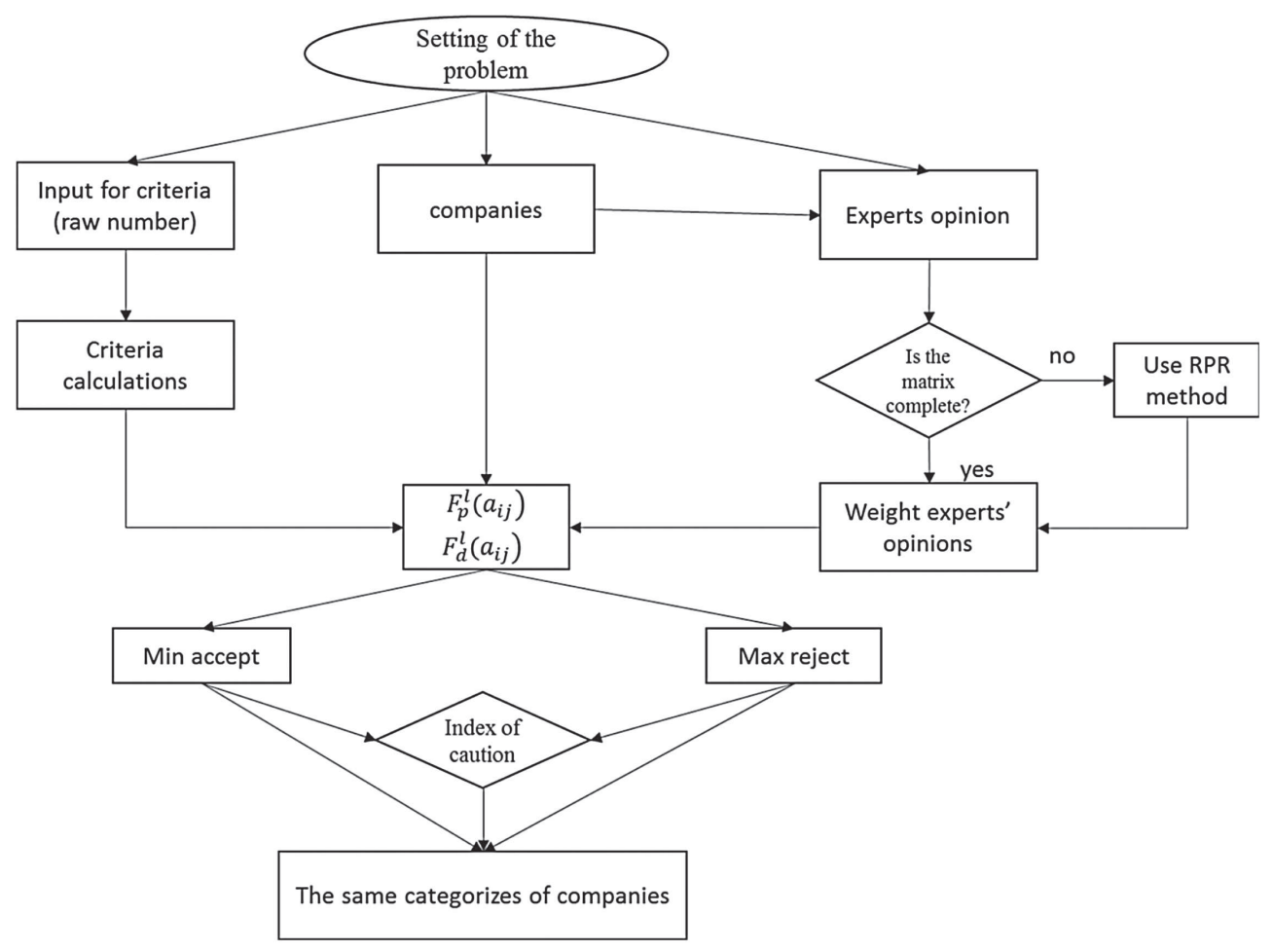

FiguRE 1. Steps of classifying alternatives based on criteria.

TABLE 1. Effective criteria list in share.

\begin{tabular}{llll}
\hline \hline Number & Criteria & Sub-dimension & References \\
\hline 1 & Return on assets & ROA & {$[20,23,37,48]$} \\
2 & Dividend payout ratio & DPR & {$[14,18,35]$} \\
3 & Operating cash flow & OCASH & {$[4,33]$} \\
4 & Sales volatility & SV & {$[27,28,36]$} \\
5 & Accounts receivable growth & AR & {$[38,45]$} \\
6 & Gross profit margin growth & GP & {$[9,49]$} \\
7 & Quick ratio & QR & {$[39,46,48]$} \\
8 & Asset turnover & AT & {$[2,5,21]$} \\
9 & Expert's opinion & EO & {$[7,8]$} \\
\hline
\end{tabular}

\section{Criteria for evaluating/EXAmine COMPANy}

The Stock Exchange Experts identified eight of the most fundamental criteria for evaluating and rating companies on the Stock Exchange. The technical and psychological perspective of the experts has been identified as the last criterion due to its high importance in selection of stocks.

These 9 criteria are listed in Table 1:

Now each of these criteria evaluate:

(1) Return on assets: ROA is a profitability ratio that provides how much profit a company is able to generate from its assets. In other words, it gives an investor an idea as to how efficient a company's management is 
at using its assets to generate earnings. ROA is highly industry-dependent. When it is used as a criterion to evaluate a company $\mathrm{X}$, it should be compared with the company's ROA in previous years or ROAs for similar companies. The higher ROA ratio is better because it shows that a company can make more earnings from less investment. The formula is defined as follows:

$$
\mathrm{ROA}=\frac{\text { Net Income }}{\text { Average total assests }} .
$$

(2) Dividend payout ratio (DPR): the dividend payout ratio is the ratio of the total amount of dividends paid out to shareholders relative to the net income of the company. It is the percentage of earnings paid to shareholders in dividends.

$$
\mathrm{DPR}=\frac{\text { Dividends }}{\text { Net income for the same period }} .
$$

(3) OCASH: operating cash flow is a measure of cash flow provided by the principal operations and business activities which generate revenue for the company and not by any other source of cash in balance sheet. OCASH is commonly presented in cash flow statement.

(4) Sales volatility: this ratio shows the rate of increase or decrease in sales in similar periods and is measured by the following formula:

$$
\mathrm{SV}=\frac{S_{n}-S_{n-1}}{S_{n-1}} \times 100 .
$$

In the above formula $S_{n}$ shows the amount of sale in the given period $n$.

(5) Accounts receivable growth (AR): accounts Receivable is any amount of money, generated from the sale of goods or services or loans, owed by customers for purchases made on credit. The amount of account receivable growth is calculated by the following formula.

$$
\mathrm{ARG}=\frac{\mathrm{AR}_{n}-\mathrm{AR}_{n-1}}{\mathrm{AR}_{n-1}} \times 100 .
$$

In this formula, $\mathrm{AR}_{n}$ indicates the amount of accounts receivable in the period $n$.

(6) Gross profit margin growth: gross profit is the total revenue minus the costs associated with producing and selling its products, or the costs associated with providing its services. Gross profit appears on a company's income statement and can be calculated by subtracting the cost of goods sold (COGS) from revenue (sales). The gross profit determines the efficiency of a company in using its labor and equipment. Gross profit is used to calculate gross profit margin. Gross profit margin is calculated by subtracting cost of goods sold (COGS) from total revenue and dividing that number by total revenue. In other words, it measures how efficiently a company uses its materials and labor to produce and sell products profitably. Therefore, we can examine company's efficiency over time measuring gross profit margin growth. The gross profit margin varies widely from industry to industry. Gross profit margin growth is calculated by the below formula.

$$
\mathrm{GPMG}=\frac{\mathrm{GPM}_{n}-\mathrm{GPM}_{n-1}}{\mathrm{GPM}_{n-1}} \times 100 .
$$

In this formula, $\mathrm{GPM}_{n}$ indicates gross profit in the period $n$.

(7) Quick Ratio (QR): QR is a type of liquidity ratio which measures the ability of company to meet its short-term liabilities. It is calculated by dividing current assets (excluding inventory and prepaid expenses) by current liabilities. The quick ration 1 indicates the proper situation of the company to pay off its current liabilities. A company that has a quick ratio less than 1 may not be able to fully pay off its current liabilities in the short term, while a company having a quick ratio higher than 1 can instantly convert its current liability into cash.

$$
\mathrm{QR}=\frac{\text { Cash }+ \text { Accounts Receivable }}{\text { Current Liabilities }}
$$


(8) Asset turnover: The asset turnover ratio is an efficiency ratio that measures a company's ability to generate sales from each dollar of company asset. The ratio is calculated by dividing the net sales into total assets.

$$
\text { Asset turnover }=\frac{\text { Net sales revenue }}{\text { Average total assets }} \times 100 .
$$

(9) Expert's opinion: one of the most critical factors in stock analysis is expert's opinion in stock market. There are a number of techniques used in technical analysis such as price action and analysis using indicator or reversal patterns or both of them. However, since analysts apply a combination of different techniques to select stocks, it is not possible to compare pairwise combinations of technical methods. Therefore, experts are asked to rate companies (technical analysis of companies) based on a pairwise comparison. These ratings are presented in the following matrix:

$$
\mathrm{EO}_{i}=\left[\begin{array}{llll}
a_{11} & a_{12} & \ldots & a_{1 m} \\
a_{21} & a_{22} & \ldots & a_{2 m} \\
\vdots & \vdots & \vdots & \vdots \\
a_{n 1} & a_{n 2} & \ldots & a_{n m}
\end{array}\right]
$$

$a_{m n}$ represents the priority of alternative $m$ over $n$.

$\mathrm{EO}_{i}$ represents the opinions of expert $i$.

\section{Solution Method}

In this section, a method for completing information of experts' ratings is presented and then, a method for classifying alternatives is proposed.

As explained in the Introduction section, due to the stock market uncertainties, large number of companies in the market and a variety of technical analysis ways and the lack of knowledge about some specific companies or stocks, there is incomplete information which is considered as input for the problem.

Since experts rate the stocks based on pairwise comparisons, it is possible that the experts do not have sufficient knowledge of some companies and are unable to rate some of the companies due to the uncertainty that exists. In this uncertain situation, experts are being asked to put variable $x$ instead of accurate rating of some companies then variable $x$ is calculated using the following method which is illustrated in the following steps:

\subsection{Calculating unknown values:}

The expert's opinions are expressed in linguistic terms and since linguistic opinions cannot be evaluated. The following fuzzy Table 2 is used to convert linguistic comments to numbers firstly [50]. There are many methods for fuzzy numbers, including triangular fuzzy and pentagonal fuzzy, but in this paper the simple fuzzy method is used to show other aspects of research $[26,29,30]$.

Firstly, the matrix table is set up for incomplete pairwise comparisons as follows, and then the incomplete information will be obtained using the reciprocal preference relation (RPR) [10,51]. The incomplete information matrix in which some values are unknown due to the lack of time or the uncertainty on pairwise recognition is defined as follows:

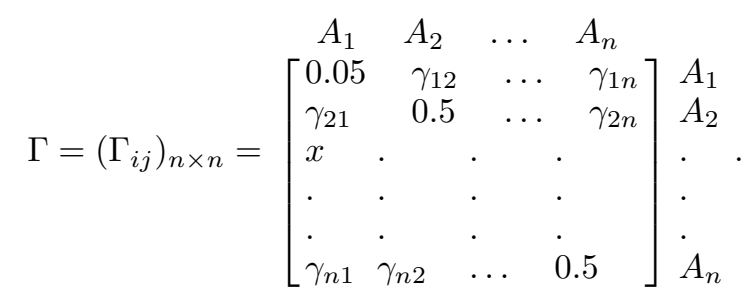


TABLE 2. Evaluation of linguistic term.

\begin{tabular}{ll}
\hline \hline Item & Value \\
\hline Extremely poor & 0.1 \\
Very poor & 0.2 \\
Poor & 0.3 \\
Slightly poor & 0.4 \\
Fair & 0.5 \\
Slightly good & 0.6 \\
Good & 0.7 \\
Very good & 0.8 \\
Extremely good & 0.9 \\
\hline
\end{tabular}

Reciprocal preference relation is represented by $\Gamma=\left(\gamma_{i j}\right)_{n \times n}$. Entry $\gamma_{i j}$ of matrix $\Gamma=\left(\Gamma_{i j}\right)_{n \times n}$ is the degree of superiority of alternative $i$ over $j$. Therefore, $\gamma_{i i}=0.5$ indicates that the two alternatives are identical and have no superiority over each other Similarly, $\gamma_{i j}>0.5$ shows the superiority of alternative $i$ over $j$. The variable $\gamma_{i j}$, which represents an unknown value, is placed in the array if there is no rating for the specific alternative [51].

The unknown value of $\gamma_{i j}$ is calculated by applying below formula and by using an intermediate element $Z_{k}$ with the assumption $i<k<j$ :

$$
m \gamma_{i j}^{k}=\frac{\gamma_{i k} \cdot \gamma_{k j}}{\gamma_{i k} \cdot \gamma_{k j}+\left(1-\gamma_{i k}\right)\left(1-\gamma_{k j}\right)} .
$$

Consequently, if there is any ambiguity in experts' opinions and the lack of sufficient information, the unknown values can be calculated applying the method described above. As mentioned above, expert opinions are presented in paired comparisons. The AHP method [16] is used to obtain expert opinion for each company separately.

Having completed the input information, the classification method used in the article will be introduced.

\subsection{A new approach to classification}

This study addresses the problems in select ability/reject ability method presented by Tchangani [42] and finally proposes a new solution. The Tchangani approach has two major flaws that hamper classification results. The problems will be discussed in detail later in this section.

In Multi Criteria Decision Making (MCDM) problems, there are several alternatives and criteria in order to classify those alternatives according to defined boundaries [10,41].

In the context of this article, the finite set $A=\left\{a_{1}, a_{2}, \ldots, a_{i}\right\}$ represents alternatives and $G=\left\{g_{1}, g_{2}, \ldots, g_{j}\right\}$ represents the criteria. Finally, the information matrix of multi-criteria problem is defined as follows:

$$
R\left(a_{i j}\right)=\left[\begin{array}{cccc}
g_{1} & g_{2} & \ldots & g_{j} \\
a_{11} & a_{12} & \ldots & a_{1 j} \\
a_{21} & a_{22} & \ldots & a_{2 j} \\
\vdots & \vdots & \vdots & \vdots \\
a_{i 1} & a_{i 2} & \ldots & a_{i j}
\end{array}\right] a_{1}
$$

As we can see in the above matrix, $a_{i j}$ represents the rating of $i$ based on the criterion $j$.

The categories are defined using boundary set $B=\left\{b_{1}, b_{2}, \ldots, b_{l}\right\}$ in a way that area around each boundary is assigned to a specific category chosen from the category set $C=\left\{c_{1}, c_{2}, \ldots, c_{l}\right\}$. The classification is nominal so the categories in set $C$ are sorted from the worst category, $c_{1}$, to the best one, $c_{l}$ (Fig. 2) 


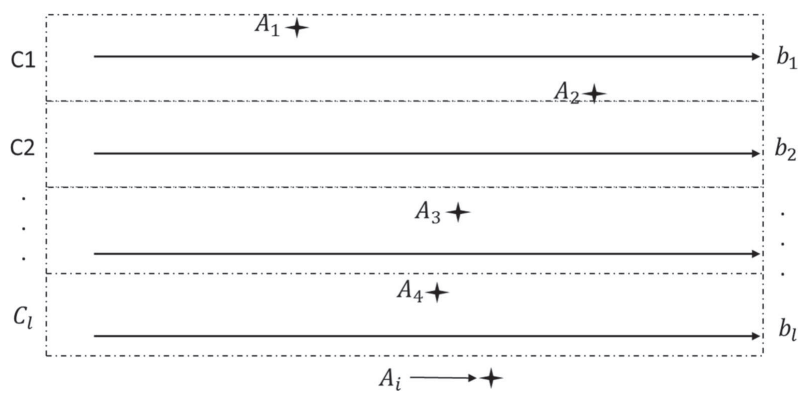

FiguRE 2. Schematic image of the placement of alternatives in the relevant categories.

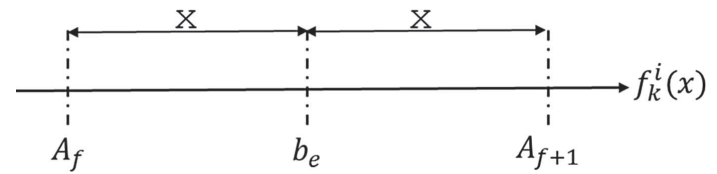

FIgURE 3 . Two points at the same distance from the boundary.

\subsection{Flaws in the Tchangani's method of acceptability/reject ability nominal classifications}

Tchangani presents a method based on acceptability/reject ability for nominal classifications by some specific criteria [42]. This approach can be useful in simple cases but in complicated ones, it cannot provide proper result. The Tchangani method has two major flaws as follows:

(1) As you can observe in the Figure 3 alternatives $A_{f}$ and $A_{f+1}, f \in[1, i]$, are located at the same distance above and below the boundary $b_{e}, e \in[1, l]$ and have the same properties relative to the boundary $b_{e}$. In Tchangani's method, the value of acceptability function assigned to the alternative below the boundary is zero and to the alternative with the same property but above the boundary is nonzero. Moreover, the value of reject ability function assigned to the alternative below the boundary is nonzero and to the alternative with the same property but above the boundary is zero. Therefore, one the major flaws in this method is that it assigns two different values to the two alternatives with the same properties.

(2) The second flaw in the Tchangani method is related to the three classification techniques called maximum acceptability, minimum reject ability and the maximum index of caution. According to Tchangani, in most cases, the three classification techniques do not provide the same answer for the same alternative.

\section{Proposed methodology}

In this method, for each element $a_{i j}$ of the matrix $R\left(a_{i j}\right)$, select ability and reject ability functions replace the rejection and acceptance functions of the Tchangani's method respectively.

$$
\begin{aligned}
& F_{d}^{l}\left(a_{i j}\right)=\left|\frac{a_{i j}-b_{i}}{\operatorname{Max}\left(b_{i}\right)-\operatorname{Min}\left(b_{i}\right)}\right| \\
& F_{p}^{l}\left(a_{i j}\right)=1-F_{d}^{l}\left(a_{i j}\right) .
\end{aligned}
$$

In the above formulas, the acceptability function $F_{p}^{l}\left(a_{i j}\right)$ shows the proximity of the alternative $a_{i j}$ to the boundary $b_{l}$ and the reject ability function $F_{d}^{l}\left(a_{i j}\right)$ shows the degree of remoteness of the alternative $a_{i j}$ to the boundary $b_{l}$. According to the formulas presented, the degree of remoteness of each alternative to any boundary in any criteria 
is based on the total distance in that criterion. Therefore, if two alternatives are at the same distance from both sides of a boundary, they receive the same score eliminating the first flaw of the Tchangani's method.

As we can see in the above formula, the sum of the acceptability and reject ability functions for alternative $a_{i j}$ to the boundary $b_{l}$ always equals one.

The classification method is presented in the next section of this paper.

\subsection{Methods of classification}

Three techniques namely minimum acceptability, maximum reject ability and the minimum index of caution are applied to classify alternatives.

\subsubsection{Method minimum acceptability}

Now, the first classification method which is based on the remoteness of a specific alternative to the boundary is proposed.

The following equation is used to classify alternative based on the minimum value of this index.

$$
C_{\left(a_{i}\right)}^{*}=\operatorname{Min}\left(\frac{\sum_{j=1}^{n} F_{d}^{l}\left(a_{i j}\right)}{\sum_{l=1}^{l} \sum_{j=1}^{n} F_{d}^{l}\left(a_{i j}\right)}\right) .
$$

In the above formula, the low value of the acceptability function shows that there are more similar properties relative to the boundary.

\subsubsection{Method maximum reject ability}

Remoteness degree of each alternative to any boundary is considered in order to classify alternatives. The following formula represents the best classification chosen with regard to degree of remoteness.

$$
C_{\left(a_{i}\right)}^{* *}=\operatorname{Max}\left(\frac{\sum_{j=1}^{n} F_{p}^{l}\left(a_{i j}\right)}{\sum_{l=1}^{l} \sum_{j=1}^{n} F_{p}^{l}\left(a_{i j}\right)}\right) .
$$

In the above formula, the high value of the reject ability function shows that there are more similar properties relative to the boundary.

\subsubsection{Method minimum index of caution}

Using the two previous methods, each alternative is assigned to a classification with the minimum index of caution as follows.

$$
C_{\left(a_{i}\right)}^{* * *}=\operatorname{Min}\left(\frac{C_{\left(a_{i j}\right)}^{*}}{C_{\left(a_{i j}\right)}^{* *}}\right) .
$$

\section{CASE Study}

Controlling and reducing the risk are important things that investors should pay attention to it. Choosing stocks with the right fundamental criteria from any industry can help investors make better decisions in buying stocks. In this way, even risk averse investors who have chosen stocks with inappropriate fundamentals have the opportunity to reduce the capital and consequently reduce the risk.

Investors intend to choose their portfolio to invest more on financially strong companies specially in critical and risky times of financial market to minimize their losses if the market falls. Moreover, classification of companies into different categories allows investors to be aware of the amount of risk they take for their investment.

Since the criteria for such classification assess fundamental aspects of companies listed in Tehran Stock Exchange, comparison of the two companies of different industries will not be rational, so to have a more accurate classification, it is better to compare companies with their own industry group. 
TABle 3. Petrochemical companies listed on the Tehran Stock Exchange.

\begin{tabular}{llllll}
\hline \hline Number & Company name & 4-digit code & Number & Company name & 4-digit code \\
\hline 1 & NORI Petrochemical & NORI & 15 & Sina Chem.Ind & SHSI \\
2 & Shiraz Petr & PSHZ & 16 & S*Iran Chem. Ind & SSIN \\
3 & Iran Amlah & AMLH & 17 & Loabiran & LEAB \\
4 & Jam Pilen & JPPC & 18 & Doode Sanati & DODE \\
5 & Iran Carbon & CRBN & 19 & Fars Chem. Ind & SHFS \\
6 & Kermanshah Petr & PKER & 20 & Goltash & GTSH \\
7 & Khorasan Petro & KRSN & 21 & Pars Int. Mfg & BMPS \\
8 & Behshahr Ind & SHOY & 22 & NiroCholor & NKOL \\
9 & PARS Petrochemical & PARS & 23 & Paksho & PASH \\
10 & Shazand Petr & PARK & 24 & Fanavaran Petr & PFAN \\
11 & Paxan & PAKS & 25 & S*Ir.Inv.Petr & IPTR \\
12 & Pardis Petr & PRDZ & 26 & Khark Petr & PKHA \\
13 & Tamin Petro & PTAP & 27 & Petro. Inv & PETR \\
14 & Khalij Fars & PKLJ & 28 & S*Parsian Oil\&Gas & PASN \\
\hline
\end{tabular}

TABLE 4. Input information of companies in Stock Exchange Market from codal website (prices in Rial).

\begin{tabular}{|c|c|c|c|c|c|c|c|c|c|c|c|c|c|}
\hline Share & $\mathrm{NP}^{1}$ & $\mathrm{OE}^{2}$ & Liability & $\mathrm{EPS}^{3}$ & $\mathrm{DPS}^{4}$ & $\mathrm{OCS}^{5}$ & $\mathrm{SLY}^{6}$ & $\mathrm{SPY}^{7}$ & $\mathrm{ARLY}^{8}$ & ARPY $^{9}$ & GPMLY $^{10}$ & GPMPY $^{11}$ & Cash \\
\hline NORI & 21153931 & 37824697 & 64457573 & 7051 & 6500 & 8573438 & 141536726 & 91057961 & 59780361 & 41488821 & 9914642 & 13181244 & 3842435 \\
\hline PSHZ & 6448061 & 5738389 & 43736214 & 1264 & 0 & 5738545 & 27194039 & 17409623 & 8216470 & 3474508 & 12916672 & 7267755 & 681998 \\
\hline AMLH & 990293 & 1376570 & 581860 & 4716 & 4400 & 1112479 & 1864656 & 1127676 & 90657 & 72865 & 1167692 & 604385 & 301192 \\
\hline JPPC & 6515706 & 8746338 & 2633150 & 3258 & 3250 & 6901400 & 17923320 & 11821853 & 616710 & 254687 & 5899488 & 3584216 & 3924603 \\
\hline CRBN & 638639 & 1712736 & 1677627 & 1836 & 1400 & 521763 & 4912069 & 2698413 & 494609 & 795741 & 1234137 & 636060 & 153614 \\
\hline PKER & 5137506 & 9944167 & 4796846 & 1456 & 600 & 3374597 & 10236593 & 5702984 & 3046540 & 812484 & 6408623 & 2924913 & 1473514 \\
\hline KRSN & 5589480 & 7637089 & 1118566 & 3123 & 2700 & 4029111 & 9508850 & 5593240 & 1577746 & 705181 & 5816315 & 2931850 & 2736538 \\
\hline SHOY & 829018 & 2459334 & 589178 & 829 & 720 & 589666 & 791635 & 731854 & 1322412 & 922689 & 791635 & 731854 & 95752 \\
\hline PARS & 58977638 & 68389949 & 22053451 & 9830 & 9300 & 14431219 & 95765540 & 66596612 & 62633687 & 33345905 & 30572667 & 20863766 & 10535502 \\
\hline PARK & 12796356 & 23936637 & 14770455 & 1588 & 1500 & 14960925 & 53001593 & 28918962 & 3302161 & 2298095 & 12858133 & 6628315 & 2839410 \\
\hline PAKS & 945271 & 2082709 & 1984851 & 1751 & 875 & 665449 & 5295627 & 3789065 & 1592282 & 1581 & 1556085 & & 61 \\
\hline PRDZ & 23509679 & 33469425 & 31938277 & 2345 & 1700 & 6370320 & 51895084 & 34033862 & 29871309 & 10824268 & 25356360 & 624 & 1278344 \\
\hline PTAP & 35289228 & 140963447 & 6587813 & 433 & 400 & 16667299 & 36827238 & 18548581 & 48766068 & 28080892 & 36633516 & 183 & 1630851 \\
\hline PKLJ & 98602936 & 253014225 & 315904489 & 1078 & 360 & $183330 \backslash 06$ & 99548717 & 4993 & 429524403 & 321375265 & 98620433 & 535 & 5683437 \\
\hline SHSI & 105617 & 356538 & 188831 & 3439 & 800 & 21228 & 622085 & 267300 & 121536 & 45482 & 200198 & 55918 & 22133 \\
\hline SSIN & 3381365 & 11834142 & 2861647 & 762 & 600 & 4339586 & 9644690 & 7128783 & 2561473 & 4271998 & 3307815 & 2173012 & 2594039 \\
\hline LEAB & 1981 & 215969 & 662782 & 12 & 2 & 47842 & 354495 & 463342 & 399635 & 498626 & 59513 & 63468 & 13554 \\
\hline DODE & 222401 & 568007 & 464789 & 469 & 50 & 74216 & 1717908 & 1036304 & 207426 & & & & \\
\hline SHFS & 5852 & 680913 & 675591 & 9 & 50 & 42554 & & 94059 & 265011 & 242080 & 181898 & 120737 & 52354 \\
\hline GTSH & 776941 & 1561668 & 622143 & 1554 & 800 & 330974 & 2583089 & 1844 & 812242 & 615629 & 1121757 & 675134 & 53016 \\
\hline BMPS & 11322 & 555902 & 1233833 & 22 & 3 & 44684 & 1893110 & 1517786 & 808341 & 593434 & 339116 & 244819 & 134853 \\
\hline NKOL & 626990 & 1201258 & 763804 & 1254 & 1000 & 603812 & 1702449 & 675617 & 302775 & 139760 & 830996 & 221912 & 238048 \\
\hline PASH & 4911962 & 6301116 & 6141052 & 4052 & 3000 & 891648 & 14099141 & 7818848 & 6076195 & 3863895 & 5759301 & 2900944 & 198538 \\
\hline PFAN & 15355398 & 17683358 & 7441046 & 16164 & 16000 & 10787137 & 26505008 & 11990576 & 8763571 & 3468486 & 15853153 & 6274615 & 40952 \\
\hline IPTR & 5125194 & 31893651 & 44719870 & 256 & 150 & 5733725 & 5299729 & 2539337 & 37004909 & 17881513 & 5169040 & 2453341 & 862436 \\
\hline PKHA & 25488187 & 31984778 & 12208508 & 12744 & 10000 & 14089835 & 29622110 & 16800401 & 15221995 & 7571202 & 19899746 & 9738558 & 7059726 \\
\hline PETR & 18143 & 3047439 & 3188387 & 10 & 0 & 33398 & 1170253 & 555602 & 2057185 & 1210168 & 970151 & 240916 & 62264 \\
\hline PASN & 21985993 & 85178127 & 17215909 & 543 & 400 & 8441824 & 23466719 & 23834493 & 26298504 & 19859114 & 23371373 & 23748298 & 2366290 \\
\hline
\end{tabular}

Notes. ${ }^{1}$ Net profit. ${ }^{2}$ Owners equity. ${ }^{3}$ Earning per share. ${ }^{4}$ Dividend per share. ${ }^{5}$ Operational cash flow. ${ }^{6}$ Sales in last year. ${ }^{7}$ Sales in previous years. ${ }^{8}$ Accounts receivable in last year. ${ }^{9}$ Accounts receivable in previous years. ${ }^{10}$ Gross profit margin in last year. ${ }^{11}$ Gross profit margin in previous year.

The petrochemical industry is one of the parent and employment-generating industries that play a key role in the economy of developing countries. Following Table 3 represents the names of 28 petrochemical companies listed on the Tehran Stock Exchange. 
TABLE 5. Final ratings assigned to companies by experts.

\begin{tabular}{llllllll}
\hline \hline SHARE & Expert 1 & Expert 2 & Expert 3 & SHARE & Expert 1 & Expert 2 & Expert 3 \\
\hline NORI & 1.103929 & 0.966699 & 0.838854 & SHSI & 0.940334 & 0.953629 & 1.161442 \\
PSHZ & 0.854958 & 0.803381 & 0.901509 & SSIN & 1.041619 & 0.982178 & 0.99775 \\
AMLH & 1.026163 & 0.837747 & 0.815728 & LEAB & 1.012506 & 1.037701 & 0.977865 \\
JPPC & 1.072022 & 0.933165 & 0.944906 & DODE & 0.96852 & 1.017513 & 0.999705 \\
CRBN & 1.039826 & 0.767545 & 0.98984 & SHFS & 1.004703 & 1.122502 & 1.131807 \\
PKER & 0.919788 & 0.991404 & 1.090312 & GTSH & 1.066545 & 1.068756 & 0.994515 \\
KRSN & 1.1477 & 0.924154 & 0.865086 & BMPS & 1.05597 & 1.18171 & 1.017293 \\
SHOY & 0.841944 & 1.099368 & 0.846256 & NKOL & 1.034833 & 1.053018 & 1.10194 \\
PARS & 1.005281 & 1.008965 & 1.129392 & PASH & 0.996868 & 1.088398 & 1.088561 \\
PARK & 0.98419 & 0.929048 & 1.01595 & PFAN & 0.959239 & 1.058601 & 1.142363 \\
PAKS & 0.93112 & 0.996583 & 0.97405 & IPTR & 1.041505 & 1.064159 & 0.973959 \\
PRDZ & 1.044616 & 0.990174 & 1.027739 & PKHA & 1.001224 & 0.938952 & 1.105402 \\
PTAP & 0.968043 & 1.058969 & 1.012259 & PETR & 0.928197 & 1.090463 & 0.993379 \\
PKLJ & 0.913947 & 0.93392 & 0.901702 & PASN & 1.094408 & 1.101297 & 0.960435 \\
\hline
\end{tabular}

TABLE 6. Assigning weight to experts.

\begin{tabular}{llll}
\hline \hline Experts & Expert 1 & Expert 2 & Expert 3 \\
\hline$w$ & 0.4 & 0.3 & 0.3 \\
\hline
\end{tabular}

Initially, data of each company in Tehran Stock Exchange is gathered to complete input matrix based on the information published on the comprehensive database of all listed companies (www.codal.ir). Fundamental data which is used as input information is listed in Table 4.

The experts' opinions have been obtained by pairwise comparisons between companies in petrochemical industry. Since for each expert there is a 28 -by-28 matrix, all of the matrixes are not displayed. However, the matrix of the opinions of the first expert is shown in the Appendix A as an instance.

As presented in the experts' opinions table available in Appendix A, the first expert is unable to express a comparative opinion between the company of AMLH and PARS and therefore sets $x$ instead of the value. The unknown value $x$ is calculated by the following formula and by using the fifth middle index.

$$
\begin{aligned}
\gamma_{39}^{5} & =\frac{\gamma_{35} \times \gamma_{59}}{\gamma_{35} \times \gamma_{59}+\left(1-\gamma_{35}\right)\left(1-\gamma_{59}\right)} \\
& =\frac{0.2 \times 0.3}{0.2 \times 0.3+(1-0.2)(1-0.3)} \\
\gamma_{39}^{5} & =0.097 .
\end{aligned}
$$

The opinions of other experts will be completed applying the presented method, if any incomplete information is observed, and eventually the final ratings of each expert will be obtained with the help of AHP method, which is given in the Table 5 as follows.

Since each expert has its own weight, we have weighted them with the help of professionals and according to the Table 6 .

After specifying the experts' opinions criteria, applying the information in the codal website given in Table 4 and the formulas presented in the criteria section, the criteria final table is identified as follows. Calculations are not given in the article due to the clarity. 
TABLE 7 . The boundaries of criteria for the companies in chemical industry.

\begin{tabular}{lcrrrrrrrl}
\hline \hline SHARE & ROA & DPR & OCASH & DEL SELL & DELL AR & DEL GPM & QR & AT & expert opinion \\
\hline$b_{1}$ & 50 & 300 & 1000000 & 1000 & 150 & 150 & 400 & 100 & 1.1 \\
$b_{2}$ & 30 & 200 & 600000 & 600 & 70 & 70 & 300 & 50 & 1 \\
$b_{3}$ & 20 & 100 & 300000 & 200 & 30 & 30 & 150 & 30 & 0.9 \\
$b_{4}$ & 0.2 & 0 & 20000 & -80 & -30 & -20 & 15 & 6 & 0.8 \\
\hline
\end{tabular}

TABLE 8. Degree of proximity to the boundary $b_{1}$.

\begin{tabular}{|c|c|c|c|c|c|c|c|c|c|}
\hline SHARE & $\mathrm{ROA}$ & DPR & OCASH & DEL SELL & DELL AR & DEL GPM & $\mathrm{QR}$ & $\mathrm{AT}$ & FM \\
\hline NORI & 0.06541 & 0.07697 & 0.85867 & 0.09718 & 0.06538 & 0.11424 & 0.08695 & 0.04536 & 0.04325 \\
\hline PSHZ & 0.08248 & 0.11111 & 0.53725 & 0.09710 & 0.00835 & 0.04724 & 0.10957 & 0.05323 & 0.09131 \\
\hline AMLH & 0.00126 & 0.07656 & 0.01275 & 0.09616 & 0.07752 & 0.03712 & 0.09600 & 0.00566 & 0.07166 \\
\hline JPPC & 0.01619 & 0.07417 & 0.66909 & 0.09757 & 0.00485 & 0.05582 & 0.06567 & 0.06797 & 0.03991 \\
\hline CRBN & 0.06953 & 0.08287 & 0.05422 & 0.09444 & 0.11595 & 0.03658 & 0.10429 & 0.05305 & 0.05809 \\
\hline PKER & 0.03380 & 0.09585 & 0.26923 & 0.09470 & 0.07714 & 0.02019 & 0.08825 & 0.03612 & 0.03984 \\
\hline KRSN & 0.03088 & 0.07909 & 0.34344 & 0.09568 & 0.01621 & 0.03374 & 0.00413 & 0.01017 & 0.03857 \\
\hline SHOY & 0.05088 & 0.07894 & 0.04652 & 0.10204 & 0.06585 & 0.09270 & 0.04597 & 0.08751 & 0.06649 \\
\hline PARS & 0.03393 & 0.07607 & 152281 & 0.09837 & 0.03838 & 0.06762 & 0.01969 & 0.00696 & 0.02088 \\
\hline PARK & 0.03780 & 0.07613 & 158287 & 0.09431 & 0.06562 & 0.03661 & 0.10344 & 0.04365 & 0.04549 \\
\hline PAKS & 0.05971 & 0.09260 & 0.03793 & 0.09879 & 0.09218 & 0.01736 & 0.08806 & 0.03569 & 0.05050 \\
\hline PRDZ & 0.03136 & 0.08426 & 0.60888 & 0.09748 & 0.01603 & 0.06845 & 0.08729 & 0.02442 & 0.02844 \\
\hline PTAP & 0.05820 & 0.07690 & 177634 & 0.09274 & 0.04712 & 0.03327 & 0.10534 & 0.08870 & 0.03386 \\
\hline PKLJ & 0.07289 & 0.09874 & 196519 & 0.09266 & 0.07182 & 0.03289 & 0.7568 & 0.09752 & 0.06805 \\
\hline SHSI & 0.06835 & 0.10250 & 0.11097 & 0.08923 & 0.01063 & 0.07060 & 0.09348 & 0.01663 & 0.03309 \\
\hline SSIN & 0.06022 & 0.08195 & 0.37864 & 0.09925 & 0.11731 & 0.06391 & 0.06345 & 0.04063 & 0.03310 \\
\hline LEAB & 0.11105 & 0.10494 & 0.10795 & 0.10530 & 0.10485 & 0.10211 & 0.09745 & 0.07052 & 0.03345 \\
\hline DODE & 0.06351 & 0.10716 & 0.10496 & 0.09611 & 0.11381 & 0.02675 & 0.10095 & 0.07841 & 0.03979 \\
\hline SHFS & 0.11059 & 0.09465 & 0.10855 & 0.09826 & 0.08675 & 0.06493 & 0.10188 & 0.00054 & 0.00808 \\
\hline GTSH & 0.03218 & 0.09204 & 0.07585 & 0.09876 & 0.07288 & 0.05480 & 0.07530 & 0.02161 & 0.02015 \\
\hline BMPS & 0.11015 & 0.10606 & 0.10831 & 0.10034 & 0.07024 & 0.07286 & 0.09338 & 0.00683 & 0.00663 \\
\hline NKOL & 0.04037 & 0.08158 & 0.04492 & 0.08724 & 0.02059 & 0.08135 & 0.09501 & 0.01580 & 0.01466 \\
\hline PASH & 0.02348 & 0.08369 & 0.01228 & 0.09462 & 0.05725 & 0.03364 & 0.08595 & 0.01574 & 0.01784 \\
\hline PFAN & 0.02480 & 0.07445 & 110965 & 0.09043 & 0.00164 & 0.00174 & 0.08129 & 0.00650 & 0.02075 \\
\hline IPTR & 0.01619 & 0.07417 & 0.66909 & 0.09757 & 0.00485 & 0.05582 & 0.06567 & 0.06797 & 0.03991 \\
\hline PKHA & 0.06953 & 0.08287 & 0.05422 & 0.09444 & 0.11595 & 0.03658 & 0.10429 & 0.05305 & 0.05809 \\
\hline PETR & 0.11091 & 0.11111 & 0.10959 & 0.09150 & 0.04939 & 0.09980 & 0.09626 & 0.09602 & 0.03836 \\
\hline PASN & 0.06365 & 0.08383 & 0.84374 & 0.10304 & 0.07258 & 0.09908 & 0.06739 & 0.09111 & 0.01619 \\
\hline
\end{tabular}

Each criterion has a different boundary; it is not correct to consider the same boundary for each criterion. Therefore, a specific boundary is defined for each criterion. Boundaries of the criteria obtained by the professionals are given in Table 7 as follows.

Applying the information of criteria numbers for each company and Table 7 and in acceptability function (14) the proximity of each alternative to the each defined boundary is calculated. The results for the boundary $b_{1}$ is shown in Table 9. The calculations for boundaries $b_{2}, b_{3}$ and $b_{4}$ are omitted here because the calculations for these boundaries are the same as those for boundary $b_{1}$.

The values of the acceptability function for the information in Table 8 represents the proximity of each company to the $b_{1}$ boundaries. In fact, the value of the reject ability function is equal to the distance of the acceptability function value to one. That is why it is not mentioned here. 
TABLE 9. Categorizing companies with minimum acceptability.

\begin{tabular}{llllllllll}
\hline \hline SHARE & $b_{1}$ & $b_{2}$ & $b_{3}$ & $b_{4}$ & SHARE & $b_{1}$ & $b_{2}$ & $b_{3}$ & $b_{4}$ \\
\hline NORI & 0.27645 & 0.24109 & 0.22364 & 0.25877 & SHSI & 0.27196 & 0.24209 & 0.21181 & 0.27414 \\
PSHZ & 0.29343 & 0.24179 & 0.22231 & 0.24384 & SSIN & 0.30391 & 0.21994 & 0.20697 & 0.26919 \\
AMLH & 0.27129 & 0.22690 & 0.21893 & 0.35645 & LEAB & 0.49009 & 0.26327 & 0.15163 & 0.09500 \\
JPPC & 0.23118 & 0.22957 & 0.25081 & 0.31261 & DODE & 0.35513 & 0.24562 & 0.19011 & 0.20913 \\
CRBN & 0.36049 & 0.22836 & 0.17986 & 0.26433 & SHFS & 0.30891 & 0.24264 & 0.21199 & 0.23647 \\
PKER & 0.22426 & 0.20241 & 0.21438 & 0.35923 & GTSH & 0.33394 & 0.20004 & 0.15908 & 0.30694 \\
KRSN & 0.19665 & 0.21361 & 0.25248 & 0.34548 & BMPS & 0.37858 & 0.25750 & 0.17382 & 0.19011 \\
SHOY & 0.46268 & 0.17586 & 0.10087 & 0.25777 & NKOL & 0.24218 & 0.19594 & 0.21926 & 0.34261 \\
PARS & 0.23704 & 0.23402 & 0.24713 & 0.28130 & PASH & 0.24593 & 0.19233 & 0.21008 & 0.35166 \\
PARK & 0.25625 & 0.23894 & 0.24401 & 0.27457 & PFAN & 0.21927 & 0.24091 & 0.24811 & 0.29171 \\
PAKS & 0.30515 & 0.22140 & 0.18599 & 0.29261 & IPTR & 0.23118 & 0.22957 & 0.23942 & 0.29983 \\
PRDZ & 0.25084 & 0.22872 & 0.23259 & 0.28687 & PKHA & 0.36049 & 0.22836 & 0.17043 & 0.24072 \\
PTAP & 0.25547 & 0.23365 & 0.24106 & 0.26796 & PETR & 0.38077 & 0.24312 & 0.18800 & 0.18811 \\
PKLJ & 0.27404 & 0.24580 & 0.23065 & 0.24764 & PASN & 0.29306 & 0.23967 & 0.21361 & 0.25365 \\
\hline
\end{tabular}

TABLE 10. Categorizing companies with maximum proximity remoteness.

\begin{tabular}{llllllllll}
\hline \hline SHARE & $b_{1}$ & $b_{2}$ & $b_{3}$ & $b_{4}$ & SHARE & $b_{1}$ & $b_{2}$ & $b_{3}$ & $b_{4}$ \\
\hline NORI & 0.24548 & 0.25152 & 0.25451 & 0.24849 & SHSI & 0.24858 & 0.25051 & 0.25247 & 0.24844 \\
PSHZ & 0.24476 & 0.25099 & 0.25324 & 0.25101 & SSIN & 0.24494 & 0.25282 & 0.25404 & 0.24820 \\
AMLH & 0.24891 & 0.25118 & 0.25329 & 0.24662 & LEAB & 0.23803 & 0.24934 & 0.25490 & 0.25773 \\
JPPC & 0.25284 & 0.25308 & 0.25160 & 0.24248 & DODE & 0.24362 & 0.25027 & 0.25363 & 0.25248 \\
CRBN & 0.24399 & 0.25118 & 0.25432 & 0.25050 & SHFS & 0.24620 & 0.25048 & 0.25245 & 0.25087 \\
PKER & 0.25266 & 0.25491 & 0.25366 & 0.23877 & GTSH & 0.24602 & 0.25237 & 0.25431 & 0.24730 \\
KRSN & 0.25541 & 0.25369 & 0.24972 & 0.24118 & BMPS & 0.24330 & 0.24961 & 0.25397 & 0.25312 \\
SHOY & 0.24154 & 0.25295 & 0.25605 & 0.24945 & NKOL & 0.25046 & 0.25316 & 0.25180 & 0.24459 \\
PARS & 0.25367 & 0.25453 & 0.25088 & 0.24091 & PASH & 0.25021 & 0.25290 & 0.25201 & 0.24488 \\
PARK & 0.24817 & 0.25323 & 0.25334 & 0.24526 & PFAN & 0.22796 & 0.25772 & 0.26060 & 0.25373 \\
PAKS & 0.24697 & 0.25157 & 0.25334 & 0.24813 & IPTR & 0.25284 & 0.25308 & 0.25160 & 0.24248 \\
PRDZ & 0.24989 & 0.25279 & 0.25235 & 0.24497 & PKHA & 0.24399 & 0.25118 & 0.25432 & 0.25050 \\
PTAP & 0.24816 & 0.25549 & 0.25332 & 0.24303 & PETR & 0.24186 & 0.25043 & 0.25386 & 0.25385 \\
PKLJ & 0.24151 & 0.25148 & 0.25721 & 0.24980 & PASN & 0.24319 & 0.25163 & 0.25575 & 0.24942 \\
\hline
\end{tabular}

Now it is time to categorize companies in petrochemical industry using three methods explained previously.

Method 1 (minimum acceptability): this technique actually shows the final proximity of the sum of the criteria of each alternative in one boundary to the other boundaries. The value of acceptability function is obtained by formula (14).

Method 2 (maximum reject ability): in this technique each alternative belongs to a set with maximum distance to the related boundary. The remoteness is calculated by formula (15).

Method 3 (minimum index of caution): in this technique, using the output of the previous techniques, the ratio of proximity to remoteness is calculated by formula (16).

The outputs of this methods for petrochemical industry are presented in Tables 9-11.

In this section, we review the results provided previously and determine which companies belong to which category. The Table 12 demonstrates the related classification for each alternative based on the methods discussed previously. 
TABLE 11. Categorizing companies with minimum index of caution.

\begin{tabular}{llllllllll}
\hline \hline SHARE & $b_{1}$ & $b_{2}$ & $b_{3}$ & $b_{4}$ & SHARE & $b_{1}$ & $b_{2}$ & $b_{3}$ & $b_{4}$ \\
\hline NORI & 1.12618 & 0.95850 & 0.87855 & 1.04175 & SHSI & 1.09405 & 0.96638 & 0.83896 & 1.10345 \\
PSHZ & 1.19887 & 0.96334 & 0.88110 & 0.96270 & SSIN & 1.24075 & 0.86993 & 0.81470 & 1.08456 \\
AMLH & 1.08988 & 0.90333 & 0.73272 & 128225 & LEAB & 2.05892 & 1.05587 & 0.59487 & 0.36863 \\
JPPC & 0.91434 & 0.90709 & 0.95161 & 1.23650 & DODE & 1.45773 & 0.98144 & 0.74956 & 0.82831 \\
CRBN & 1.47744 & 0.90915 & 0.67014 & 0.96094 & SHFS & 1.25471 & 0.96870 & 0.83972 & 0.94258 \\
PKER & 0.88759 & 0.79404 & 0.84566 & 150279 & GTSH & 1.35733 & 0.79264 & 0.62555 & 1.24116 \\
KRSN & 0.76992 & 0.84200 & 101227 & 1.39715 & BMPS & 1.55600 & 1.03160 & 0.68440 & 0.75106 \\
SHOY & 1.91549 & 0.69523 & 0.38161 & 1.05732 & NKOL & 0.96697 & 0.77399 & 0.87078 & 1.40079 \\
PARS & 0.93442 & 0.91942 & 0.98404 & 1.17080 & PASH & 0.98290 & 0.76050 & 0.83360 & 1.43606 \\
PARK & 1.03257 & 0.94358 & 0.94171 & 1.08551 & PFAN & 0.96190 & 0.93478 & 0.95210 & 1.14967 \\
PAKS & 1.23559 & 0.88007 & 0.74751 & 1.14489 & IPTR & 0.91434 & 0.90709 & 0.95161 & 1.23650 \\
PRDZ & 1.00378 & 0.90478 & 0.91969 & 1.17714 & PKHA & 1.47744 & 0.90915 & 0.67014 & 0.96094 \\
PTAP & 1.02944 & 0.91452 & 0.94788 & 1.11413 & PETR & 1.57431 & 0.97082 & 0.74059 & 0.74101 \\
PKLJ & 1.13469 & 0.97742 & 0.89258 & 1.00312 & PASN & 1.20508 & 0.95248 & 0.83521 & 1.01696 \\
\hline
\end{tabular}

TABLE 12. Categorizing companies in petrochemical industry.

\begin{tabular}{llllllll}
\hline \hline SHARES & $\begin{array}{l}\text { min } \\
\text { acceptability }\end{array}$ & $\begin{array}{l}\text { max reject } \\
\text { ability }\end{array}$ & $\begin{array}{l}\text { min index } \\
\text { of caution }\end{array}$ & SHARES & $\begin{array}{l}\text { min } \\
\text { acceptability }\end{array}$ & $\begin{array}{l}\text { max reject } \\
\text { ability }\end{array}$ & $\begin{array}{l}\text { min index } \\
\text { of caution }\end{array}$ \\
\hline NORI & $b_{3}$ & $b_{3}$ & $b_{3}$ & SHSI & $b_{3}$ & $b_{3}$ & $b_{3}$ \\
PSHZ & $b_{3}$ & $b_{3}$ & $b_{3}$ & SSIN & $b_{3}$ & $b_{3}$ & $b_{3}$ \\
AMLH & $b_{1}$ & $b_{1}$ & $b_{1}$ & LEAB & $b_{4}$ & $b_{4}$ & $b_{4}$ \\
JPPC & $b_{1}$ & $b_{1}$ & $b_{1}$ & DODE & $b_{3}$ & $b_{3}$ & $b_{3}$ \\
CRBN & $b_{3}$ & $b_{3}$ & $b_{3}$ & SHFS & $b_{3}$ & $b_{3}$ & $b_{3}$ \\
PKER & $b_{2}$ & $b_{2}$ & $b_{2}$ & GTSH & $b_{3}$ & $b_{3}$ & $b_{3}$ \\
KRSN & $b_{1}$ & $b_{1}$ & $b_{1}$ & BMPS & $b_{3}$ & $b_{3}$ & $b_{3}$ \\
SHOY & $b_{3}$ & $b_{3}$ & $b_{3}$ & NKOL & $b_{2}$ & $b_{2}$ & $b_{2}$ \\
PARS & $b_{2}$ & $b_{2}$ & $b_{2}$ & PASH & $b_{2}$ & $b_{2}$ & $b_{2}$ \\
PARK & $b_{3}$ & $b_{3}$ & $b_{3}$ & PFAN & $b_{1}$ & $b_{1}$ & $b_{1}$ \\
PAKS & $b_{3}$ & $b_{3}$ & $b_{3}$ & IPTR & $b_{2}$ & $b_{2}$ & $b_{2}$ \\
PRDZ & $b_{3}$ & $b_{3}$ & $b_{3}$ & PKHA & $b_{3}$ & $b_{3}$ & $b_{3}$ \\
PTAP & $b_{2}$ & $b_{2}$ & $b_{2}$ & PETR & $b_{4}$ & $b_{4}$ & $b_{4}$ \\
PKLJ & $b_{3}$ & $b_{3}$ & $b_{3}$ & PASN & $b_{3}$ & $b_{3}$ & $b_{3}$ \\
\hline
\end{tabular}

In this part of the article, the results are reviewed and which company belongs to which class is determined. In Table 12, it is observed that the three methods have the same result.

\section{The Classification RESUlts}

As shown in the Table 12, PETR and LEAB have the most similar properties to the boundary 4 so they are classified in category $C_{4}$. In the same manner, AMLH, PFAN, KRSN and JPPC are assigned to the category $C_{1}$. 16 companies are closer to the boundary $C_{3}$ and therefore are assigned to the category $C_{2}$. Eventually, the remaining six companies which have the same properties with the boundary 2 are classified in category $C_{2}$.

To validate the method proposed in this section, AMLH from Class 1 and LEAB from class 4 are chosen to analyze. At first glance at the Petrochemical industry's final criteria Table 12, this category is noticed. AMLH 


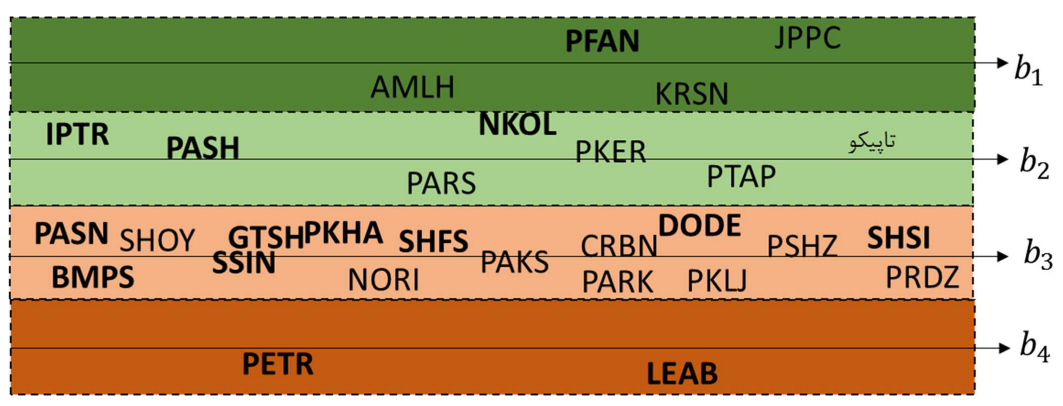

Figure 4. Schematic form of classification of Petrochemical companies in Tehran Stock Exchange Market.

company experienced a significant increase in sales volatility compared to the same period last year while in the same period LEAB company experienced decrease in sales volatility.

Also, by considering other criteria, it can be realized that AMLH's OCASH is more than twenty-three times the amount of OCASH in the LEAB company. Moreover, in other criteria such as net profit which is considered as one of the most important profitability in AMLH, this value is higher than the value calculated for the LEAB. Therefore, the proposed method, which adopts all the criteria presented, is considered the most appropriate classification. The same applies to other companies.

PKER and CRBN, assigned to class 2 \& 3, respectively, can be a good example. Despite it's strength in dividend-to-profit ratio and increased volatility in sales over two consecutive periods as well as an increase in the AT criteria, CRBN's performance is poorer compared to PKER's when considering other criteria. All of these factors put CRBN in class $C_{3}$. The schematic diagram (Fig. 4) classifies the Petrochemical companies by fundamental and financial ratios.

\section{MANAGERIAL INSIGHT}

One of the main concerns of the managers is to choose one alternative from several alternatives. Due to various criteria and ambiguity in the decision making environment, this has become a dilemma for the managers. In Tchangani's method the outputs of all three methods introduced for decision-making is not the same, so the managers be confused. Also, in some cases that the alternative is places on the boundary, the Tchangani's method fails to give an output. In the proposed method, all the errors in Tchangani's method have been eliminated and a more accurate and comprehensive method of classification have been provided. Moreover, specifically in stock market, investors have to face with a variety of criteria and a large number of alternatives, each of which is very time consuming to review and may take many trade opportunities from investors. Therefore, a method which can classify companies in the shortest time possible based on criteria that are of particular importance to the investor is very valuable.

\section{Conclusion}

This study aimed to classify companies at petrochemical industry in the intuitive fuzzy environment using the proposed similarity approach under uncertain environment and despite incomplete information in experts' opinions. Petrochemical industry is one of the most important and critical industries in Stock Exchange Market. Considering the fact that fundamental criteria are crucial in determining the future of a company, criteria are selected from the factors involved in the firm's foundation. Moreover, since the experiences and opinions of experts in the capital market are crucial and essential, a specific criterion is dedicated to experts' opinions.

In this study, one of the nominal similarity methods proposed by Tchangani is analyzed and then the flaws in the method are explained. One of the flaws of the Tchangani's method is that it does not equal the similarity of 
the two alternatives, one at the top and the other at the bottom of the boundary. In addition, Tchangani assigned the value zero to the alternative below the boundary regardless of the alternative's distance from the boundary. Moreover, in some cases, infinite quantities are observed at the point where the boundary is located, leading to different outputs for the three techniques in Tchangani's classification method and eventually to confusion in choosing the company to invest in. The proposed method in the intuitive fuzzy environment eliminates the flaws in Tchangani's method despite uncertainty and incomplete information.

The information in the Figure 4 can be used in several ways, including:

(1) Risk-averse investors can invest in companies around the boundary $b_{1}$.

(2) The progress of companies can be compared through changing the period of input information from year to month and studying the changes made to the figure as a result of these changes.

(3) Companies around the boundary $b_{4}$ which are not currently in a good situation to invest should be considered in order to make a long-term investment when they have good vision and reasonable prices.

Selecting the stocks and comparing the companies in each industry, as well as identifying the amount of risk involved, requires identification and classification of the companies in each industry.

There are three types of time investment in terms of time in the capital market, including short, medium and long term, each of which has its own criteria. Changing the criteria presented in this study, researchers can evaluate companies on the basis of short, medium and long term investment.

Considering the future vision of each company and the viability of these prospects, long-term investments can be made in companies which are in lower categories and are currently less expensive.

In addition, the risk of investment in each class should be determined so that investors can choose categories to invest in based on the amount of risk they can take.

By changing the input criteria of the problem, researchers can apply the classification method presented in this paper in different contexts. Researchers are also advised to use triangular or trapezoidal fuzzy inputs to convert the input information into a fuzzy environment. Researchers are also advised to use triangular or trapezoidal fuzzy inputs to convert input information into a fuzzy environment. In addition, if there is no specific boundary in their field, they can use the area instead of the boundary.

\section{Appendix A.}

See Table A.1. 


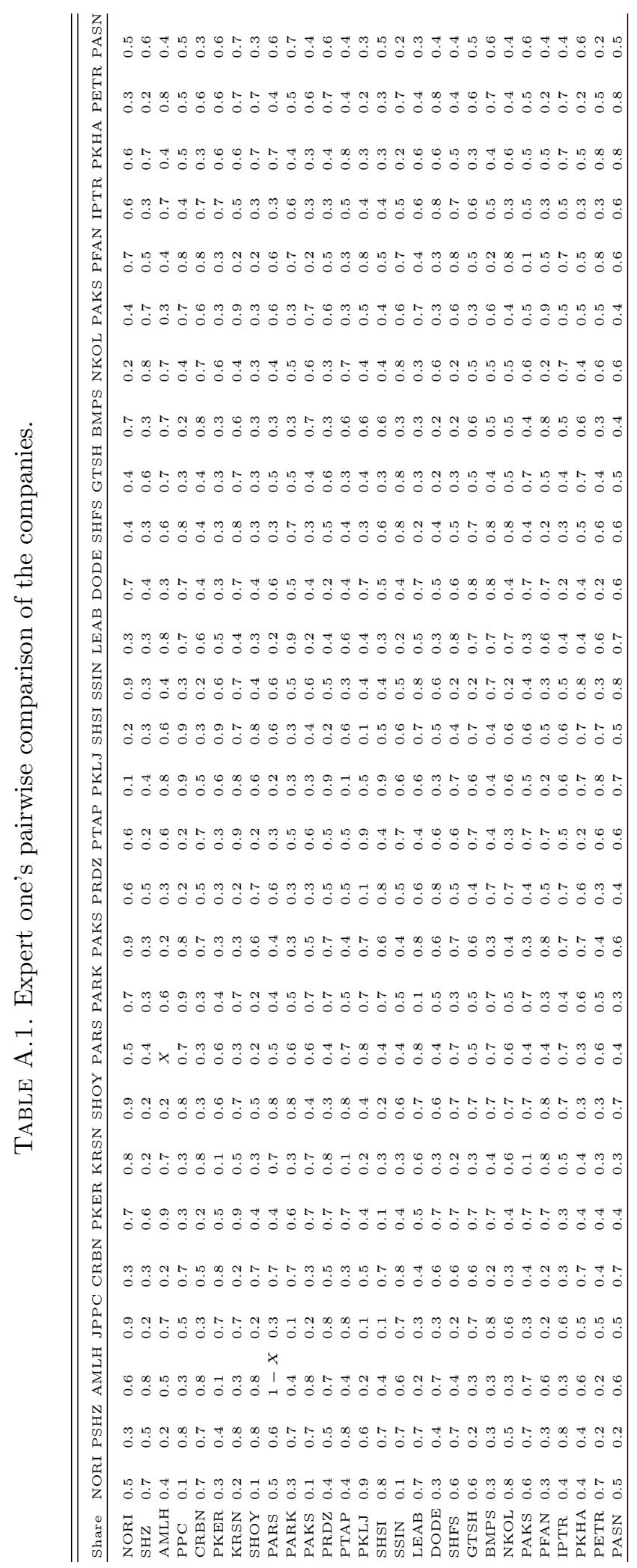


Acknowledgements. The study is not funded by any agency The authors do hereby declare that there is no conflict of interests of other works regarding the publication of this paper This article does not contain any studies with human participants or animals performed by any of the authors.

\section{REFERENCES}

[1] I.N. Agustin, The integration of fundamental and technical analysis in predicting the stock price. J. Manage. Maranatha 18 (2019) 93-102.

[2] B.L. Ahrendsen and A.L. Katchova, Financial ratio analysis using ARMS data. Agric. Finance Rev. 72 (2012) $262-272$.

[3] S.H.M. Al-Dini, D.H. Dehavi and E. Zarezadeh, Fitting the relationship between financial variables and stock price through fuzzy regression case study: Iran Khodro Company. Int. J. Bus. Soc. Sci. 2 (2011) 140-146.

[4] A. Andreas, Analysis of operating cash flow to detect real activity manipulation and its effect on market performance. Int. J. Econ. Financial Issues 7 (2017) 524-529.

[5] T.L. Asmi, Current ratio, debt to equity ratio, total asset turnover, return on asset, price to book value sebagai faktor penentu return saham. Manage. Anal. J. 3 (2014).

[6] A. Ayodele, A. Charles and A. Marion, Stock price prediction using artificial neural network with hybridyzed market indicator. J. Emerg. Trends Comput. Inf. Sci. 3 (2012) 1-9.

[7] S. Basak, S. Kar, S. Saha, L. Khaidem and S.R. Dey, Predicting the direction of stock market prices using tree-based classifiers. North Am. J. Econ. Finance 47 (2019) 552-567.

[8] E. Beyaz, F. Tekiner, X.J. Zeng and J. Keane, Comparing technical and fundamental indicators in stock price forecasting. In: 2018 IEEE 20th International Conference on High Performance Computing and Communications; IEEE 16th International Conference on Smart City; IEEE 4th International Conference on Data Science and Systems (HPCC/SmartCity/DSS). IEEE (2018) 1607-1613.

[9] A.R. Bionda and N.M. Mahdar, Pengaruh gross profit margin, net profit margin, return on asset, dan return on equity terhadap pertumbuhan laba pada perusahaan manufaktur di bursa efek indonesia. Kalbisocio J. Bisnis Komunikasi 4 (2017).

[10] A.K. Birjandi, F. Akhyani, R. Sheikh and S.S. Sana, Evaluation and selecting the contractor in bidding with incomplete information using MCGDM method. Soft Comput. 23 (2019) 10569-10585.

[11] Q. Cai, D. Zhang, B. Wu and S.C. Leung, A novel stock forecasting model based on fuzzy time series and genetic algorithm. Proc. Comput. Sci. 18 (2013) 1155-1162.

[12] S. Emir, H. Dincer and M. Timor, A stock selection model based on fundamental and technical analysis variables by using artificial neural network and support vector machines. Rev. Econ. Finance 2 (2012) 106-122.

[13] D. Escobari and M. Jafarinejad, Investors' uncertainty and stock market risk. J. Behav. Finance 20 (2019) $304-315$.

[14] R.R. Fitri, M.N. Hosen and S. Muhari, Analysis of factors that impact dividend payout ratio on listed companies at Jakarta islamic index. Int. J. Acad. Res. Account. Finance Manage. Sci. 6 (2016) 87-97.

[15] J. Gao, Y. Hou, F. Fan and F. Liu, Complexity changes in the US and China's stock markets: differences, causes, and wider social implications. Entropy 22 (2020) 75.

[16] B. Gaudenzi and A. Borghesi, Managing risks in the supply chain using the AHP method. Int. J. Logistics Manage. 17 (2006) $114-136$.

[17] N. Ghorui, A. Ghosh, E.A. Algehyne, S.P. Mondal and A.K. Saha, AHP-TOPSIS inspired shopping mall site selection problem with fuzzy data. Mathematics 8 (2020) 1380.

[18] A. Gill, N. Biger and R. Tibrewala, Determinants of dividend payout ratios: evidence from United States. Open Bus. J. 3 (2010).

[19] S.A.I. Hussain, U.K. Mandal and S.P. Mondal, Decision maker priority index and degree of vagueness coupled decision making method: a synergistic approach. Int. J. Fuzzy Syst. 20 1551-1566.

[20] W. Idawati and A. Wahyudi, Effect of earning per shares (EPS) and return on assets (ROA) against share price on coal mining company listed in Indonesia stock exchange. J. Res. Dev. Manage. 7 (2015) 79-91.

[21] I.P. Jansen, S. Ramnath and T.L. Yohn, A diagnostic for earnings management using changes in asset turnover and profit margin. Contemp. Account. Res. 29 (2012) 221-251.

[22] Y. Karaca, Y.D. Zhang and K. Muhammad, Characterizing complexity and self-similarity based on fractal and entropy analyses for stock market forecast modelling. Expert Syst. App. 144 (2020) 113098.

[23] P. Kupiec and Y. Lee, What factors explain differences in return on assets among community banks. J. Money Credit Banking 17 (2012) 69-83.

[24] Z. Li, D. Yang, L. Zhao, J. Bian, T. Qin and T.Y. Liu, Individualized indicator for all: stock-wise technical indicator optimization with stock embedding. In: Proceedings of the 25th ACM SIGKDD International Conference on Knowledge Discovery 83 Data Mining (2019) 894-902.

[25] S. Maity, S.K. De and S. Prasad Mondal, A study of an EOQ model under Lock Fuzzy Environment. Mathematics 7 (2019) 75.

[26] S. Maity, S.K. De and S.P. Mondal, A study of a backorder EOQ model for cloud-type intuitionistic dense fuzzy demand rate. Int. J. Fuzzy Syst. 22 (2020) 201-211.

[27] H.A. Marfatia, Investors' risk perceptions in the US and global stock market integration. Res. Int. Bus. Finance (2020) 101169.

[28] M. Minnis and A. Sutherland, Financial statements as monitoring mechanisms: Evidence from small commercial loans. J. Account. Res. 55 (2017) 197-233. 
[29] S.P. Mondal, Interval valued intuitionistic fuzzy number and its application in differential equation. J. Intell. Fuzzy Syst. 34 (2018) 677-687.

[30] S.P. Mondal and M. Mandal, Pentagonal fuzzy number, its properties and application in fuzzy equation. Future Comput. Inf. J. 2 (2017) 110-117.

[31] A. Namdari and Z.S. Li, Integrating fundamental and technical analysis of stock market through multi-layer perceptron. In: 2018 IEEE Technology and Engineering Management Conference (TEMSCON) IEEE (2018) 1-6.

[32] R. Naranjo and M. Santos, A fuzzy decision system for money investment in stock markets based on fuzzy candlesticks pattern recognition. Expert Syst. App. 133 (2019) 34-48.

[33] H. Nguyen and T. Nguyen, The prediction of future operating cash flows using accrual-based and cash-based accounting information: empirical evidence from Vietnam. Manage. Sci. Lett. 10 (2020) 683-694.

[34] I.K. Nti, A.F. Adekoya and B.A. Weyori, A systematic review of fundamental and technical analysis of stock market predictions. Art. Intell. Rev. (2019) 1-51.

[35] A.N. Odum, C.G. Odum, R.I. Omeziri and C.F. Egbunike, Impact of dividend payout ratio on the value of firm: a study of companies listed on the Nigerian stock exchange. Indonesian J. Contemp. Manage. Res. 1 (2019) 25-34.

[36] E.A. Osadchy, E.M. Akhmetshin, E.F. Amirova, T.N. Bochkareva, Y. Gazizyanova and A.V. Yumashev, Financial Statements of a Company as an Information Base for Decision-making in a Transforming Economy. Eur. Res. Stud. 2 (2018) 339-350.

[37] S.P. Pangestu and A. Wijayanto, Pengaruh Return on Assets (ROA), Return on Equity (ROE), Earning Per Share (EPS), Price Earning Ratio (PER), DAN Debt to Equity Ratio (DER) Terhadap return saham. J. Admin. Bisnis 10 (2020) 63-71.

[38] S.Y. Paul, C. Guermat and S. Devi, Why do firms invest in accounts receivable? An empirical investigation of the Malaysian manufacturing sector. J. Accounting Emerg. Econ. 8 (2018) 166-184.

[39] A. Purnomo, Influence of the ratio of profit margin, financial leverage ratio, current ratio, quick ratio against the conditions and financial distress. Indonesian J. Bus. Accounting Manage. 1 (2018) 218.

[40] M. Sayumwe and B. Amroune, Directors characteristics and stock market performance in Canada. J. Econ. Financial Stud. 5 (2017) $1-15$.

[41] F. Shen, J. Xu and Z. Xu, An outranking sorting method for multi-criteria group decision making using intuitionistic fuzzy sets. Inf. Sci. 334 (2016) 338-353.

[42] A.P. Tchangani, Selectability/rejectability measures approach for nominal classification. J. Uncertain Syst. 3 (2009) $257-269$.

[43] J. Traina, Is Aggregate Market Power Increasing? Production Trends Using Financial Statements. Stigler Center for the Study of the Economy and the State, University of Chicago (2018).

[44] Q. Wang, W. Xu and H. Zheng, Combining the wisdom of crowds and technical analysis for financial market prediction using deep random subspace ensembles. Neurocomputing 299 (2018) 51-61.

[45] J.E. Wanyoike, Accounts Receivable management practices and financial performance of manufacturing firms in Kenya. Acad. Res. Insight J. 1 (2017) 1-15.

[46] L. Warrad, The impact of liquidity through quick ratio on share price: evidence from Jordanian banks. Eur. J. Accounting Auditing Finance Res. 2 (2014) 9-14.

[47] L.H. Warrad, The effect of market valuation measures on stock price: an empirical investigation on Jordanian banks. Int. J. Bus. Soc. Sci. 8 (2017) 67-74.

[48] D.P. Wijaya and I.B.P. Sedana, Effects of quick ratio, return on assets and exchange rates on stock returns. Am. J. Humanities Soc. Sci. Res. 4 (2020) 323-329.

[49] X. Yu, G. Dosi, M. Grazzi and J. Lei, Inside the virtuous circle between productivity, profitability, investment and corporate growth: an anatomy of Chinese industrialization. Res. Policy 46 (2017) 1020-1038.

[50] L.A. Zadeh, G.J. Klir and B. Yuan, Fuzzy Sets, Fuzzy Logic, and Fuzzy Systems: Selected Papers. Vol. 6 of Advances in Fuzzy Systems Applications and Theory by Lotfi A. Zadeh. World Scientific, Binghamton, NY (1996).

[51] X. Zhang, B. Ge, J. Jiang and Y. Tan, Consensus building in group decision making based on multiplicative consistency with incomplete reciprocal preference relations. Knowl.-Based Syst. 106 (2016) 96-104. 